Original Research Article

\title{
An analysis of skin appendageal tumors: 10 year study
}

\author{
Rajan J. ${ }^{1}$, Mathew A.S. ${ }^{2}$, Jayalekhmi B. ${ }^{3}$ \\ ${ }^{1}$ Dr. Junu Rajan, Assistant Professor, ${ }^{2}$ Dr. Apuca Susan Mathew, Professor, ${ }^{3}$ Dr. B Jayalekhmi, Professor and HOD; all \\ authors are affiliated with Department of Pathology, Dr SMCSI Medical College, Karakonam, Thiruvanthapuram, \\ Kerala, India.
}

Corresponding Author: Dr. Junu Rajan, Assistant Professor, Department of Pathology, Dr SMCSI Medical College, Karakonam, Thiruvanathapuram. Email: junurajan@gmail.com

\begin{abstract}
Introduction: Skin appendageal tumors are wide spectrum of disorders that differentiate towards one or more adnexal structures. Objective: To determine the prevalence of skin appengeal tumours. Materials and methods: This is a record based cross sectional study from the Department of pathology, Dr SMCSI Medical College between $1^{\text {st }}$ January 2004 to $1^{\text {st }}$ November 2014 who were diagnosed with skin tumours by histopathology and these cases were reviewed classified and analysed according to the patient's age, gender, and localization. Results: 166 cases were studied during this study period, males 68 and females 98. Mean age of presentation in this study was 34 years. Tumours with follicular differentiation constituted the maximum, 81 cases $(48.8 \%)$, followed by eccrine differentiation constituting 22 cases (13.25\%): tumours with apocrine differentiation 21 cases $(12.66 \%)$ and sebaceous differentiation 9 cases (5.4\%). One case each of sebaceous adenoma and sebaceous carcinoma were the only malignant tumours. Conclusion: Skin adnexal tumours are relatively uncommon and the incidence of benign skin adnexal tumours are more common compared to the malignant ones.
\end{abstract}

Keywords: Skin appendageal tumors, Benign, Malignant, Histopathology

\section{Introduction}

Skin appendageal tumours of the skin are really complex and have confusing nomenclature. Different types show marked variation in histological appearance and there is significant morphological overlap between the different types [1]. Even though most of the adnexal tumors are benign lesions, malignant variety also occur.

There are many inherited syndromes in which cutaneous adnexal tumors are a feature, and failure to recognize these associations may have serious implications [1]. Most of the benign present as a symptomatic papules or nodules and often troublesome to diagnose clinically however anatomic location, number and distribution of lesions provide important clue [2]. Few clinicopathological studies are available on adnexal tumours. The clinical history is essential for diagnosing skin appendageal tumours on biopsy [3].

Appendageal tumors are clinically non-descript, flesh colored, solitary or multiple papules or nodule. Some of them found to have penchant for certain parts of body

Manuscript received: $14^{\text {th }}$ June 2018

Reviewed: $24^{\text {th }}$ June 2018

Author Corrected: $30^{\text {th }}$ June 2018

Accepted for Publication: $5^{\text {th }}$ July 2018 like eccrine poroma which is most common is lower limb, but can occur in other parts also $[4,5]$. No known provoking conjucture is evident in the vast majority of appendgael tumours. There are some cases in which the reason is an autosomal dominant mutation in a tumour suppressor gene [6,7]. Adnexal tumours arising from the skin are usually missed clinically and often confirmed by histopathology [7,8]. They are however confirmed by histopathology, and immuno histochemistry may help in confirming the diagnosis. This study is done to determine the prevalence of skin appendageal tumours

\section{Materials and Methods}

Place and type of study: The present study includes the cases from 1st January 2004 to 1st November 2014. The study was done in the Department of pathology from Dr SMCSI Medical College. This is a record based cross sectional study.

Sampling method, collection and inclusion criteria: The clinic pathological data was taken from the medical record department in Dr SMCSI Medical College for the given period. The cases which are included were 


\section{Original Research Article}

diagnosed with skin tumours by histopathology and these cases were reviewed classified and analyzed according to the patient's age, gender, and localization and from which department the specimen was received.

\section{Results}

166 cases were studied during this study period. Among them, males were 68 (41\%) and females were 98 (58\%). Mean age of presentation in this study was 34 years.

Tumours with follicular differentiation constituted the maximum, 81 cases $(48.8 \%)$, followed by eccrine differentiation constituting 22 cases (13.25\%): tumours with apocrine differentiation 21 cases (12.66\%) and sebaceous differentiation 9 cases $(5.4 \%)$. (Table I)

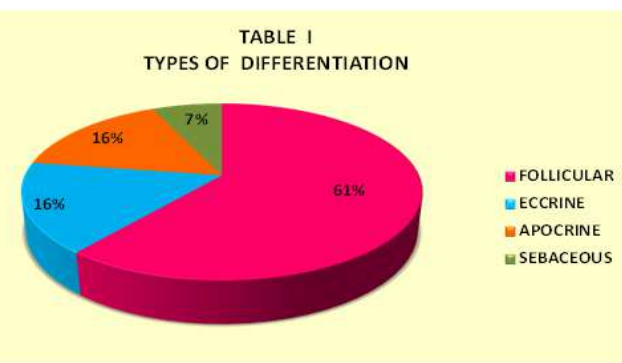

Pilomatricoma constituted the commonest follicular tumour, 45 cases (57\%). Other cases in the follicular differentiation proliferating trichilemmal tumour 25 cases (33\%), trichoepithelioma 4 cases (5\%), trichofolliculoma 2 cases (3\%), trichoblastoma and tricholemmoma one case each. There was one malignant proliferating trichilemmal tumour also. It was seen in male of age 68 years presented as a scalp swelling. (Table II)

Eccrine poroma was the commonest in eccrine differentiation 7 cases (32\%), followed by nodular hidradenoma 6 cases (27\%), chondroid syringoma 5 cases $(23 \%)$ and eccrine spiradenoma 4 cases $(18 \%)$. (Table III)

\begin{tabular}{|c|c|c|}
\hline \multicolumn{2}{|c|}{ Table- II: Follicular Differentiation } \\
\hline Types & Number of cases & Percentage \\
\hline Pilomatricoma & 45 & $57 \%$ \\
\hline Proliferating trichelimmeal cyst & 25 & $33 \%$ \\
\hline Trichoepithelioma & 4 & $5 \%$ \\
\hline Trichofolloiculoma & 2 & $3 \%$ \\
\hline Trichoblastoma & 1 & $1 \%$ \\
\hline Tricholemmoma & 1 & $1 \%$ \\
\hline Malignant Proliferating Trichelimmeal cyst & 1 & $1 \%$ \\
\hline
\end{tabular}

Among tumours with apocrine differentiation, syringe cyst adenoma papilliferum were the commonest comprising 8 cases $(40 \%)$ The other tumours were hidradenoma papilliferum 5 cases $(30 \%)$, cylindroma (20\%), a case of apocrine hidrocystoma (5\%) and tubular apocrine adenoma (5\%) one each. (Table IV)

\begin{tabular}{|c|c|c|}
\hline \multicolumn{2}{|c|}{ Table- III: Eccrine Differentiation } \\
\hline Types & Number of cases & Percentage \\
\hline Eccrine Poroma & 7 & $32 \%$ \\
\hline Nodular Hidradenoma & 6 & $27 \%$ \\
\hline Choroid Syringoma & 5 & $23 \%$ \\
\hline Eccrine Spiradenoma & 4 & $18 \%$ \\
\hline
\end{tabular}

\begin{tabular}{|c|c|c|}
\hline \multicolumn{2}{|c|}{ Table-IV: Apocrine Differentiation } \\
\hline Types & Number of cases & Percentage \\
\hline SyringocystadenomaPappiliferum & 8 & $40 \%$ \\
\hline HidroadenomaPappiliferum & 6 & $30 \%$ \\
\hline Cylindroma & 4 & $20 \%$ \\
\hline Apocrine Hidrocystoma & 1 & $5 \%$ \\
\hline Tubular Apocrine Adenoma & 1 & $5 \%$ \\
\hline
\end{tabular}




\section{Original Research Article}

\begin{tabular}{|c|c|c|}
\hline \multicolumn{3}{|c|}{ Table-V: Sebaceous Differentiation } \\
\hline Types & Number of cases & Types \\
\hline Nevus Sebaceous & 7 & $78 \%$ \\
\hline Sebaceous Adenoma & 1 & $11 \%$ \\
\hline Sebaceous Carcinoma & 1 & $11 \%$ \\
\hline
\end{tabular}

In sebaceous differentiation, we got 7 cases $(78 \%)$ of nevusse baceous, one case each of sebaceous adenoma and sebaceous carcinoma (11\%). (Table V)

There was one interesting case of giant Hidradenoma papilliferum which presented at an unusual location in the lower extremity for a 68 -year-old male. This was clinically diagnosed as infected papilloma (ms 5.5 X 4 X 4cm). (Figure:1)

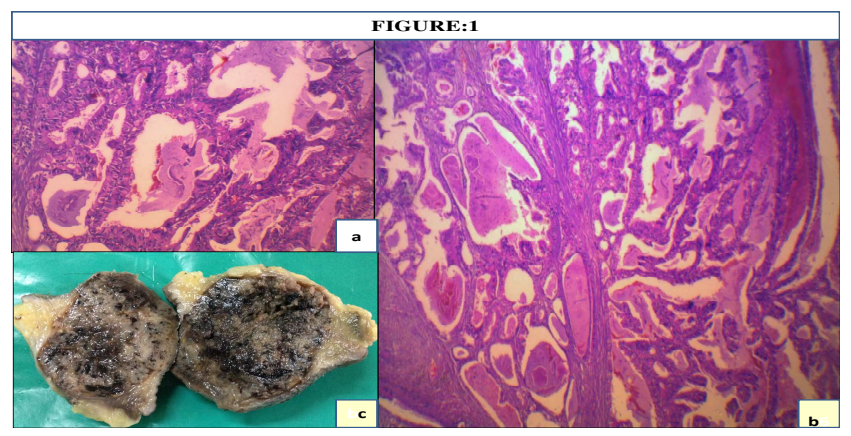

Fig 1: Hidradenoma pappiliferum a) $(\mathrm{H}$ and $\mathrm{E}, \times 100) \mathrm{b})(\mathrm{H}$ and $\mathrm{E}, \times 400)$ Numerous papillary projections c) Cut surface of the lower extremity swelling showing a grey white to grey brown well circumscribed lesion

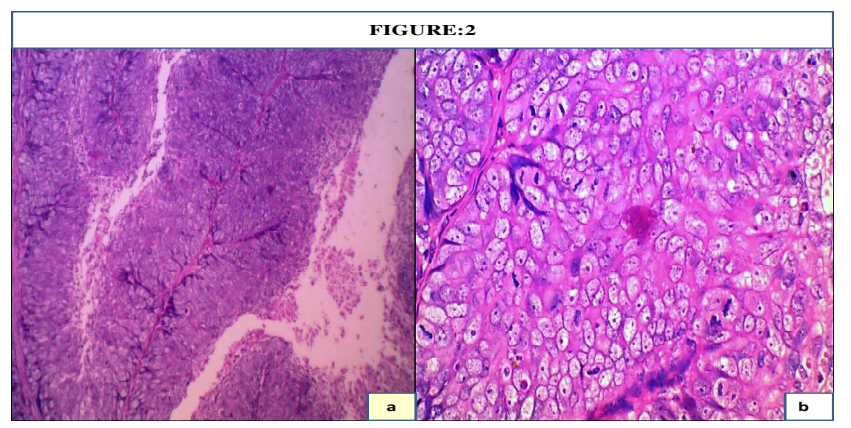

Fig 2: Sebaceous carcinoma. a) $(\mathrm{H}$ and $\mathrm{E}, \times 100) \mathrm{b})(\mathrm{H}$ and $\mathrm{E}, \times 400)$ lesion showing marked atypia

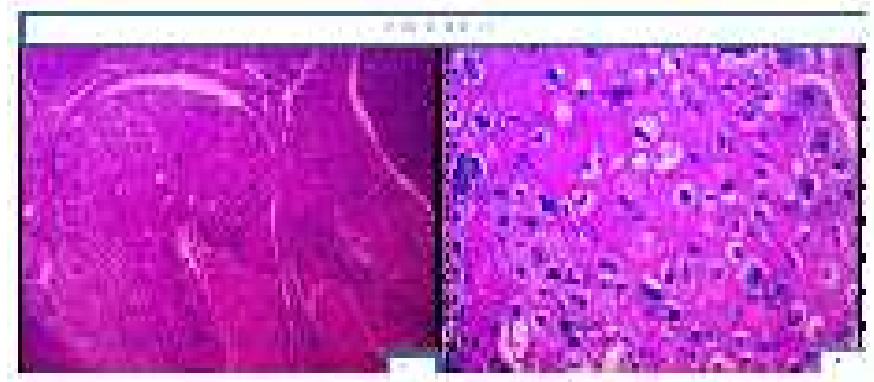

Fig 3: Malignant poliferating trichilemmal tumour a) $(\mathrm{H}$ and $\mathrm{E}, \times 100) \mathrm{b})(\mathrm{H}$ and $\mathrm{E}, \times 400)$

Among the 166 cases, there were only two malignant cases; one case each of sebaceous carcinoma (Figure: 2) and malignant proliferating trichilemmal tumours (Figure: 3) Both of which were diagnosed clinically as benign lesions lipoma and sebaceous cyst respectively

\section{Discussion}

Skin adnexal tumours are comparatively rare tumors comprising $0.5 \%$ of all the biopsies received in our institution. Most skin adnexal tumours are not that common enough for the histopathologist to get a quick 
familiarity with them [10]. In a similar descriptive study in Parguay, they received $1.4 \%$ of skin adnexal tumours[11]. In a study in Nigeria by Samaila et al[9], they received $0.9 \%$ of skin adexal tumours. Another descriptive study by Kaur et al [12] in north Indiaalso received $0.3 \%$ of skin adnexal tumours. Most of the tumors in this study were benign $98.8 \%$ while malignant was only $1.2 \%$. Others studiesin which benign tumour predominance are Samaila et al[9], (88.5\%), Radhika et al[3] (77.14\%), Saha et al[13] (100\%) Sharma et al [14] (80.36\%), Rajalakshmi et al [15] (90.48\%), El Ochi et al [16](97.7\%), Nair [17] $(100 \%)$ and Kaur et al [12]. Skin appendageal tumours are very difficult to diagnose. Traditional criteria of cytological and nuclear atypia alone do not make a diagnosis of a tumor malignant [14]. Bernard Ackerman first elaborated the significance of silhouettes/ architectural attributes which can make it easier in differentiating between benign and malignant tumours.

The features of benign tumors are symmetrical, vertically orientated with $\mathrm{V}$-shape with uniform collection of epithelial cells, dense fibrotic stromal reactions and absence of necrosis, atypia, and mitosis. Whereas the malign tumours show asymmetry, horizontal orientation of tumor, irregular arrangement of cells with infiltration, necrosis, atypia, mitosis, and diminished sclerotic stroma. Therefore, it is very important to examine the slide under scanner view to evaluate the configuration of adnexal tumours to differentiate benign and malignant ones. In this study we have used these criteria $[14,18,19,20]$. Males were $68(41 \%)$ and females were 98 (58\%). Radhikaet al, Hesari et al, Saha et al and Nair also found as light increase in female preponderance $[3,11,13,17]$. Mean age of presentation in this study was 34 years. Radhika et al[3], Samaila et al [9], Saha et al [13], Rajalakshmi et al [15], El Ochi et al [16] also observed the same mean age. But Sharmaet al [14] got 40-60 years and Nair [17] got $10-20$ years. In our study tumours with follicular differentiation constituted the maximum, 81 cases $(48.8 \%)$, followed by eccrine differentiation constituting 22 cases $(13.25 \%)$ : tumours with apocrine differentiation 21 cases $(12.66 \%)$ and sebaceous differentiation 9 cases (5.4\%). Similar observation were seenin study of Kaur et al [12] and El Ochi et al [16] while Sharma et al[14] Nair [ 17], Vaishnav et al [21], Reddy et al [22] Gayathri et al [23] and Pujani et al [24] found sweat gland differentiation to be most common followed by follicular and seb-aceous differentiation. Pilomatricoma constituted the commonest tumour in benign nature. Similar observation was found in Rajalekshmi et al[15], El Ochi et al[16] and Kaur et al [12]. While Samaila et al [9] had got eccrine acrospiroma, Radhika et al[3] found

\section{Original Research Article}

nodular hideradenoma, Sharma et al found clear cell hideradenoma and Saha et al[13] and Nair [17] found syringoma as most common one. We got an interesting case of a man presented with a lower extremity swelling and was diagnosed as giant ectopic Hidradenoma papilliferum. It usually occurs in women in the perineal and perianal region $[1,25,26]$. In males, the most common site is perianal region. It is usually a few millimeters in size but in our case it was measuring 5.5 $\mathrm{x} 4.4 \mathrm{~cm}$. Vang R also reported an ectopic hidradenoma pappileferum in a male in the lower extremity. In contradiction toanogenital hidradenoma papilliferum, nearly one half of the patients with ectopic hidradenoma papilliferum are men [27].

\section{Conclusion}

Skin appendageal tumoursare relatively uncommon. Clinical diagnosis of appendageal tumors is immensely troublesome because most of the tumors have similar clinical presentation and most of their symptoms are non specific. Benign tumours are more common compared to the malignant ones and malignancy is often hard to diagnose clinically. Histopathological examination becomes essential in diagnosis and it is the gold standard in the diagnosis of skin appendageal tumours.

\section{What is new in this study?}

A case of giant ectopic hidradenoma papilliferum was diagnosed in lower extremity. Ectopic sites of hidradenoma papilliferum are usually eyelid, nasal area, and breast. In lower extremity it has been the second case reported so far.

\section{Funding: Nil, Conflict of interest: None initiated Permission from IRB: Yes}

\section{References}

1. Ahmed TS, Priore JD, Seykora JT. Tumours of epidermal appendages. In: Elder DE, editor. Lever's Histopathology of Skin. $11^{\text {th }}$ ed. Philadelphia: Lippencott Williams and Wilkins; 2015. p. 851-909.

2. Stantaylor R, Perone JB, Kaddu S, Kerl H. Appendage Tumors and Hamartomas of the Skin. In: Wolff K, Goldsmith L, Katz S, Gilchrest BA, Paller AS, Leffell DJ, ed. Fitzptrick's Dermatology in General Medicine. 7 th edition. New York: McGraw Hill; 2008. p. $1068-87$.

3. Radhikha K, Phaneendra BV, Rukmangadha N, Reddy MK. A study of biopsy confirmed skin adnexal tumors: Experience at a tertiary care teaching hospital. J Clin Sci Res 2013July ; 2(3):132-8. 
4. Ramirez Claudia C, Berman Brian. Cutaneous Sign and Syndromes Associated with internal Malignancies.

Skin Med. 2005: 4(2): 84-90.

5. U Jindal, R Patel. Study Of Adnexal Tumors Of The Skin: A Three Year Study Of 25 Cases. The Internet Journal of Pathology. 2012 Volume 13 Number 3.

6. Le BoitP, Burg G,Weed on D Sarasin A. Pathology and genetics of skin tumors. Lyon: IARC Press; 2006

7. Penneys NS. Immunohistochemistry of adnexal neoplasms. J Cutan Pathol.1984 Oct;11(5):357-64.

8. Paudyal et al A clinico-histopathological study on skin appendageal tumors $\mathbf{J}$ of Pathology of Nepal (2016) Vol. 6,885-891

9. Samaila MO. Adnexal skin tumors in Zaria, Nigeria. Ann Afr Med. 2008 Mar;7(1):6-10.

10. Kamyab-Hesari et al Clinicopathological Study of 1016 Consecutive Adnexal Skin Tumors Acta MedicaIranica, Vol. 51, No. 12 (2013) 879-85

11. Gonzalez L, Di Martino B, Rodriguez M, Knopfelmachler O, Lourdes Bolla, Recalde J. Clinical and epidemiological studyof adnexal tumours at the Dermatology Departmentof the Medical Sciences Faculty, National University ofAsuncion. Paraguay, 2002-2008. Folia Dermatol Peru2009; 20: 135-9

12. Kaur K. Gupta K, HemrajaniD, et al. Histopathological Analysis of Skin Adnexal Tumors: A Three Year Study of 110 Cases at A Tertiary Care Center. doi: 10.4103/ijd.IJD_380_16.

13. Saha A, Das NK, Gharami RC, Chowdhury SN, Datta PK. A clinico-histopathological study of appendageal skin tumors, affecting head and neck region in patients attending the dermatology opd of a tertiary care centre in eastern India. Indian J Dermatol 2011; 56:33-6.

14. Sharma A, Paricharak DG, Nigam JS, Rewri S, Soni PB, Omhare A, Sekar P. Histopathological study of Skin Adnexal Tumours- Institutional Study in South India. Journal of Skin cancer.2014;1-4.

\section{Original Research Article}

15. Rajalakshmi V, Selvakumar S, Rajeswari K, et al. Case series of skin adnexal tumours. DOI:10.7860/ JCDR/ 2014/8710.4844

16. El Ochi MR, Boudhas A, AllaouiM, et al. Skin adnexal tumors: Histological study about 96 cases. doi: 10.11604/pamj.2015.20.389.6202.ECollection 2015.

17. Nair PS. A clinicopathologic study of skin appendageal tumors. Indian J Dermatol Venereol Leprol. 2008 Sep-Oct;74(5):550.

18. Ackerman AB. Differentiation of benign from malignant neoplasms by silhouette. Am J Dermatopathol. 1989 Aug;11(4):297-300.

19. Cotton D, Troublesome tumours. 1: Adnexal tumours of the skin. J Clin Pathol. 1991Jul;44(7):543-8.

20. TirumalaeR , Roopa M. Benign vs. Malignant Skin Adnexal Neoplasms: How Useful are Silhouettes? doi: 10.4103/0019-5154.105282.

21. Vaishnav VP, Dharkar DD. Adnexal tumours of skin. Indian J PatholBacteriol. 1974 Jan;17(1):33-8.

22. M. K. Reddy, A. J. Veliath, S. Nagarajan, and A. L. Aurora. A clinicopathological study of adnexal tumours of skin. Indian Journal of Medical Research, vol. 75, no. 6, pp. 882-889, 1982.

23. Sri Gayathri S, EzhilvizhiAlavandar, Ashok Kumar. An Analysis of skin appendageal Tumors in South India. Journal of Evolution of Medical and Dental Sciences.2013;1(6):907 -912.

24. Pujani M, Madaan GB, JairajpuriZS, et al. Adnexal Tumors of Skin: An Experience at a Tertiary Care Center at Delhi. doi: 10. 4103/ amhsr. amhsr_339_14.

25. van der Putte SC. Mammary-like glands of the vulva and their disorders. Int J Gynecol Pathol. 1994 Apr; 13 (2):150-60.

26. Veraldi S, Schianchi-Veraldi R, Marini D. Hidradenoma papilliferum of the vulva: report of a case characterized by unusual clinicalbehavior. J Dermatol Surg Oncol. 1990 Jul;16(7):674-6.

27. Vang R, Cohen PR. Ectopic hidradenoma papilliferum: a case report and review of the literature. $\mathrm{J}$ Am Acad Dermatol. 1999 Jul;41(1):115-8.

\section{How to cite this article?}

Rajan J, Mathew A.S, Jayalekhmi B. An analysis of skin appendageal tumors: 10 year study. Trop J Path Micro 2018;4(3):265-269.doi:10. 17511/jopm.2018.i3.05 